\title{
Institutos Federais: a produção intelectual dos técnico-administrativos em educação
}

\author{
Federal Institutes: the intellectual production of administrative \\ technician in education
}

\section{Institutos Federales: la producción intelectual de técnico administrativo en educación}

Maysa Eichner da Silva Bazana ${ }^{1}$; Cloves Alexandre de Castro²; Michel Goulart da Silva ${ }^{3}$

\section{RESUMO}

Este artigo é produto de caminho metodológico da pesquisa de mestrado realizando no âmbito do ProfEPT/Polo Blumenau acerca da percepção dos Técnico-Administrativos em Educação (TAEs) sobre a concepção pedagógica do IFC. A estrutura teórica é a que busca captar o movimento real do objeto por meio das determinações ocultas na aparência revelada pelo mundo sensível. A busca por tais determinações nos exigiu averiguar 0 estado da arte da produção intelectual dessa categoria lotada nos IFs, principalmente sobre ensino, pesquisa e extensão. Para isso nos debruçamos sobre os números da coletânea "Gestão Pública: a visão dos Técnicos Administrativos em Educação das Universidades Públicas e Institutos Federais", edições de 2014 a 2020. Constatamos diversidade de temas publicados, porém, poucas publicações sobre ensino, pesquisa e extensão, o que pode demonstrar que esse profissional ainda é descaracterizado da função de educador ou/e o próprio trabalhador não se reconhece como tal.

Palavras-chave: Educação Profissional e Tecnológica; Institutos Federais; Técnico-Administrativos em Educação; Ebook GPTAE.

\begin{abstract}
This article is the product of the methodological path of the master's research carried out within the scope of ProfEPT/Polo Blumenau about the perception of Administrative Technicians in Education on the pedagogical conception of the IFC. The theoretical structure is the one that seeks to capture the real movement of the object through the determinations hidden in the appearance revealed by the sensible world. The search for such determinations required us to investigate the state of the art of the intellectual production of this category filled in the IFs, mainly on teaching, research and extension. For this, we focused on the numbers of the collection "Gestão Pública: a visão dos Técnicos Administrativos em Educação das Universidades Públicas e Institutos Federais", 2014-2020 editions. We found a diversity of published themes, however, few publications on teaching, research and extension, which can demonstrate that this professional is still not characterized as an educator or/and the worker himself does not recognize himself as such.
\end{abstract}

Keywords: Professional and Technological Education; Federal Institutes; Administrative Technician in Education; Ebook GPTAE.

\footnotetext{
${ }^{1}$ Mestranda do Curso de Mestrado Profissional em Educação Profissional e Tecnológica (ProfEPT) e Assistente em Administração do Instituto Federal Catarinense (IFC), Blumenau/SC - Brasil. E-mail: maysaesb@gmail.com

2 Pós-Doutor em Geografia Humana, Professor do Instituto Federal Catarinense (IFC) e credenciado ao Programa de Pós-Graduação em Educação Profissional Tecnológica (ProfEPT), Blumenau/SC - Brasil. E-mail: cloves.castro@ifc.edu.br

${ }^{3}$ Doutor em História e Técnico em Assuntos Educacionais do Instituto Federal Catarinense (IFC), Blumenau/SC

- Brasil. E-mail: michel.silva@ifc.edu.br
} 


\section{RESUMEN}

Este artículo es producto de la trayectoria metodológica de la investigación de maestría realizada en el ámbito del ProfEPT / Polo Blumenau sobre la percepción de los Técnicos Administrativos en Educación sobre la concepción pedagógica del IFC. La estructura teórica es la que busca captar el movimiento real del objeto a través de las determinaciones ocultas en la apariencia revelada por el mundo sensible. La búsqueda de tales determinaciones nos obligó a investigar el estado del arte de la producción intelectual de esta categoría llenada en los IFs, principalmente en enseñanza, investigación y extensión. Para ello, nos centramos en los números de la colección "Gestão Pública: a visão dos Técnicos Administrativos em Educação das Universidades Públicas e Institutos Federais", ediciones de 2014 a 2020. Encontramos diversidad de temas publicados, sin embargo, pocas publicaciones sobre enseñanza, investigación y extensión, lo que puede demostrar que este profesional todavía no se caracteriza como educador y / o el propio trabajador no se reconoce como tal.

Palabras clave: Educación Profesional y Tecnológica; Institutos Federales; Técnicos Administrativos en Educación; Libro electrónico GPTAE.

\section{INTRODUÇÃO}

Junto com a história dos Institutos Federais (IFs) está a história dos alunos e trabalhadores dessa instituição: servidores Docentes e Técnico-Administrativos em Educação (TAEs). Eles formam a comunidade acadêmica e estabelecem uma relação tripla, na qual docentes exercem a relação pedagógica direta com os alunos e os TAEs são os possibilitadores dessa relação, que também é pedagógica, a partir do momento em que assumimos o trabalho como princípio educativo. Cada ator tem a sua importância ímpar no processo do saber e o trabalho de um interfere no do outro e as ações precisam ser orgânicas.

O TAE tem prerrogativas de atuar no "Planejamento, execução e avaliação das atividades de pesquisa e extensão e de apoio ao ensino em sala de aula, nos laboratórios, oficinas, campos de experimento ou outros espaços onde ocorram a produção e a transmissão do conhecimento (...)" (BRASIL, 2006). Essa especificação geral do cargo e a nomenclatura - Técnico-Administrativo em Educação passaram a existir somente após 2005 com promulgação da Lei no 11.091, de 12 de janeiro de 2005, que "dispõe sobre a estruturação do Plano de Carreira dos Cargos Técnico-Administrativos em Educação, no âmbito das Instituições Federais de Ensino vinculadas ao Ministério da Educação" (BRASIL, 2008), conhecida como PCCTAE. Segundo pesquisa de Moura, Magalhães Car e Magalhães Ric (2015, p. 02):

No histórico da EP, o trabalho não docente, esteve vinculado a "função coadjuvante", aspecto que descaracteriza o técnico como educador e a dispensa de uma formação técnico-pedagógica adequada. Esse contexto, constituído naturalmente por relações sociais conflituosas, é permeada por interesses antagônicos em disputa, exigindo a materialização de políticas públicas que acomodam ou geram ainda mais conflitos.

Diante do histórico da categoria e do reconhecimento em Lei (PCCTAE) da atuação desses profissionais no ensino, pesquisa e extensão, nos indagamos: Quais os temas referentes aos Institutos Federais esses trabalhadores dissertam? Eles refletem criticamente e diretamente sobre 0 ensino, pesquisa e extensão que a sua Instituição de trabalho oferece?

Assim estabelecemos como nosso objetivo geral o mapeamento da produção intelectual dos TAEs dos IFs sobre as atividades de ensino, pesquisa e extensão, e definimos três objetivos específicos: levantar os autores dos artigos e suas instituições de lotação; identificar os temas discutidos e analisar quais artigos tratam diretamente das atividades de ensino, pesquisa e extensão dos Institutos 
Federais. Tudo isso com o fito de adensarmos nossas reflexões na pesquisa de mestrado realizando no âmbito do Programa de Pós-Graduação em Educação Profissional e Tecnológica (ProfEPT), polo Blumenau, que investiga olhar dos TAEs sobre o projeto pedagógico do IFC.

Para isso analisamos a coletânea "Gestão Pública: a visão dos Técnicos Administrativos em Educação das Universidades Públicas e Institutos Federais (GPTAE)", publicadas em ebook, entre 2014 e 2020. Os autores principais dos artigos dessas publicações têm a obrigatoriedade de ser TAE, e nosso foco neste trabalho são os TAEs lotados nos Institutos Federais.

\section{FUNDAMENTAÇÃO TEÓRICA}

Historicamente a Educação Profissional e Tecnológica (EPT) no Brasil esteve sustentada aos interesses das classes dominantes, que tem como base da concepção educacional a dicotomia entre trabalho manual e trabalho intelectual, se estruturando na dualidade entre formação para o trabalho voltada aos filhos da classe trabalhadora e a formação propedêutica para as elites dirigentes. Sob a égide moldada pela burguesia brasileira de "um capitalismo dependente, associado e subordinado ao capital mundial" (FRIGOTTO, 2007, p. 1048). Essa opção de projeto societário da burguesia brasileira

nunca se colocou, de fato, a preocupação de uma política de formação técnica e profissional para a maioria dos trabalhadores, para prepará-los para o trabalho complexo que os tornasse, enquanto classe detentora do capital, em condições de aproximar-se daqueles países que completaram a revolução burguesa. Isto também explica a visão reducionista de qualidade de educação dentro de uma concepção mercantil e dominantemente para formar para o trabalho simples. (FRIGOTTO, 2018, p. 126).

Mas essa perspectiva hegemônica encontra resistência na sociedade brasileira e é nessa disputa, conforme Frigotto, Ciavatta e Ramos (2006, p. 40), que se apresentam duas perspectivas da educação profissional e tecnológica:

Uma que a identifica com a educação que aborda conhecimentos associados às tecnologias utilizadas nos processos de produção e, assim, pode formar pessoas para o manejo social e profissional dessas tecnologias para ocuparem um espaço específico na divisão social e técnica do trabalho. (...) Outra (...) que, em seus termos teóricos e práticos, propiciasse a superação da concepção educacional burguesa que se pauta pela dicotomia entre trabalho manual e trabalho intelectual e entre instrução profissional e instrução geral. Nesse sentido, o conceito de educação tecnológica ganhava o sentido com o de politecnia.

A primeira perspectiva configurou modalidades específicas voltadas para a formação imediata para o trabalho, tanto no ensino médio quanto no nível superior, num movimento histórico contraditório (...). A segunda, entretanto, compreendia uma formulação política e conceitual que buscava definir o caráter unitário e politécnico que deveria ser perseguido para o ensino médio. (FRIGOTTO, CIAVATTA, e RAMOS, 2006, p. 40).

No embate desses dois projetos que em 2004 foi revogado o Decreto no 2.208/1997, que, além de proibir o ensino médio de forma integrada, também regulamentava "formas fragmentadas e aligeiradas de educação profissional, em função das alegadas necessidades do mercado" (FRIGOTTO, CIAVATTA e RAMOS, 2006, p. 31). A referida legislação foi substituída pelo Decreto no 5.154/2004, que "buscou superar a dualidade propondo o ensino médio integrado, tendo como base a ciência, o trabalho e a cultura, como a educação básica de ensino médio de travessia para a escola unitária e a formação politécnica" (FRIGOTTO, 2018, p. 146 e 147). 
No contexto dessas disputas e contradições é concebida uma nova institucionalidade que carrega uma história desde 1909, com a criação das Escolas de Aprendizes Artífices, e que resulta nos Institutos Federais (IFs), em dezembro de 2008, pela Lei no 11.892. Da transformação ou integração de unidades de ensino já existentes - Escolas Técnicas Federais, Escolas Agrotécnicas Federais, Centros Federais de Educação Tecnológica (CEFETs) - foram criados 38 IFs, que acompanhados da Universidade Tecnológica Federal do Paraná (UTFPR), CEFET Celso Suckow da Fonseca (CEFET-RJ), CEFET de Minas Gerais (CEFET-MG), Escolas Técnicas Vinculadas às Universidades Federais e Colégio Pedro II passaram a compor a Rede Federal de Educação Profissional, Científica e Tecnológica (RFEPCT), ramificada em todo o território brasileiro.

É nesta Lei específica que os IFs "possuem natureza jurídica de autarquia, detentoras de autonomia administrativa, patrimonial, financeira, didático-pedagógica e disciplinar" (BRASIL, 2008), e os define como:

instituições de educação superior, básica e profissional, pluricurriculares e multicampi, especializados na oferta de educação profissional e tecnológica nas diferentes modalidades de ensino, com base na conjugação de conhecimentos técnicos e tecnológicos com as suas práticas pedagógicas, nos termos desta Lei. (BRASIL, 2008).

Os IFs não devem ser compreendidos como um desdobramento linear das políticas de EPT, mas como produto histórico com

[...] raízes profundas que remetem às feridas crônicas da sociedade brasileira ao passo que também concebem tratamentos para elas. Trata-se, portanto, de uma ruptura com as políticas de EPT desenvolvidas até então no Brasil e teve sua possibilidade de existência condicionada pelo avanço político-organizativo da classe trabalhadora e suas vitórias pontuais na luta de classes (CICHACZEWSKI, 2020, p. 29).

Segundo Eliezer Pacheco, que esteve à frente da Secretaria de Educação Profissional e Tecnológica (SETEC) durante a criação dos IFs "no campo da operacionalização, existem alguns elementos cuja efetivação coloca em risco a potencialidade prometida. Nesse sentido, faz-se importante distinguir a concepção normativa e ideal estabelecida no campo do dever-ser, da perspectiva real desenvolvida na institucionalidade e na conjuntura dos Institutos Federais de Educação, Ciência e Tecnologia" (PACHECO, 2015, p. 39).

Em síntese, é compreensível que a gestão das instituições de ensino federais tenham certas inconsistências, que são características de uma macro conjuntura que apresenta uma dupla relação conflituosa. A primeira entre uma matriz jurídica de Administração Pública típica de um Estado mínimo e uma política de governo que tenta instituir um Estado de Bem-Estar Social e a segunda entre os interesses internos da corporação e os interesses sociais ou mesmo dos entes da Administração direta. (PACHECO, 2015, p. 44).

Além dessa questão da operacionalização do projeto de nova matriz da EPT, apresentado por Pacheco (2015), é importante trazer alguns aspectos apresentados por Frigotto (2018), após pesquisa de campo em IFs. O autor enfatiza que "pela natureza das informações colhidas e pela amplitude do universo dos IFs, não cabem generalizações" (FRIGOTTO, 2018, p. 147), e apresenta cinco aspectos de extrema importância para pensarmos essa nova institucionalidade: "1. Os IFs e as tendências da formação profissional e técnica"; "2. Os IFs e a perda da identidade de uma rede federal"; "3. Políticas de desenvolvimento institucional e organização pedagógica e priorizações dentro da verticalidade"; "4. Organização das ofertas formativas"; "5. Bases materiais dos IFs e recursos para financiamento". 
Diante das constatações de sua pesquisa FRIGOTTO (2018)i coloca como grande desafio a ampliação e a qualificação dessa Instituição. Essa qualificação, diante as contradições que permeiam essa nova institucionalidade, pode pender para os interesses do Capital ou da Classe Trabalhadora. Os trabalhadores dessas instituições (além dos alunos, coletivo de dirigentes, comunidade local e poder público) são peças importantes desse jogo contraditório, pois são eles que trabalham na efetivação/operacionalização dessa política pública. Os IFs contam com trabalhadores docentes e TAEs, que são servidores públicos, regidos pela Lei no 8112/1990, que dispõe sobre o regime jurídicos dos servidores públicos civis da União, das autarquias e das fundações públicas federais, com diferentes planos de carreira.

A criação de uma nova institucionalidade, alicerçada em uma história secular da EPT, também se reflete nos trabalhadores da instituição. Pela criação aligeirada e sem uma discussão consistente na base das instituições que vieram a integrar os IFs, dessa nova proposta resultou na dificuldade dos servidores dessas antigas instituições entenderem a nova institucionalidade e de participarem da discussão da criação, para expressarem suas opiniões (contrariedade/ideias/acordos). Já a expansão rápida abriu vagas para novos servidores. Muitos desses novos concursados assumiram as vagas nos IFs apenas como espera para serem chamados em um concurso com melhor remuneração e, também, vinham com a cultura educacional das universidades. Ao tratar essas questões de junção de tempos Frigotto (2018, p. 131) salienta que "se tem potencialidades educativas marcadas pela experiência e sedimentação, também tem o complicador da natureza dessa memória e de como juntar tempos com história e cultura tão diversas e mudança de institucionalidade e criar uma nova identidade".

Essas questões se apresentam para todos os trabalhadores dos IFs, mas, como nossa pesquisa tem recorte o trabalhador $\mathrm{TAE}$, dos IFs, precisamos focar nessa categoria. A estrutura do cargo desses trabalhadores está regulamentada na Lei no 11.091, de 12 de janeiro de 2005, que "dispõe sobre a estruturação do Plano de Carreira dos Cargos Técnico-Administrativos em Educação, no âmbito das Instituições Federais de Ensino vinculadas ao Ministério da Educação" (BRASIL, 2008, grifo nosso), conhecida como PCCTAE. Cabem aqui algumas considerações iniciais sobre esse cargo, que muitas vezes causam confusões:

A Lei no 11.091/2005 regulamenta o trabalho TAE nas Universidades Federais (UFs) e na RFEPCT independente da Instituição Federal de Ensino (IFE). Por causa de nosso recorte de pesquisa, apesar de a legislação abarcar trabalhadores das Universidades, pela delimitação da pesquisa na EPT, vamos estudar essa categoria no espaço dos IFs.

O Cargo TAE tem trezentos e vinte e cinco (325) denominações diferentes, organizados em 5 (cinco) níveis de classificação (A, B, C, D e E). Segundo a Lei, nível de classificação é o "conjunto de cargos de mesma hierarquia, classificados a partir do requisito de escolaridade, nível de responsabilidade, conhecimentos, habilidades específicas, formação especializada, experiência, risco e esforço físico para o desempenho de suas atribuições" (BRASIL, 2005). Exemplificando: quando falamos da denominação do cargo de Servente de Limpeza (Nível A) ou Padeiro (Nível B) ou Porteiro (Nível C) ou Assistente em Administração (Nível D) ou Técnico em Assuntos Educacionais (Nível E), estamos nos referindo a um Técnico-Administrativo em Educação (TAE). Todas as 325 diferentes denominações se remetem aos TAEs e tem uma atribuição geral em comum: 
Art. $8^{\circ}$ São atribuições gerais dos cargos que integram o Plano de Carreira, sem prejuízo das atribuições específicas e observados os requisitos de qualificação e competências definidos nas respectivas especificações:

I - planejar, organizar, executar ou avaliar as atividades inerentes ao apoio técnicoadministrativo ao ensino;

II - planejar, organizar, executar ou avaliar as atividades técnico-administrativas inerentes à pesquisa e à extensão nas Instituições Federais de Ensino;

III - executar tarefas específicas, utilizando-se de recursos materiais, financeiros e outros de que a Instituição Federal de Ensino disponha, a fim de assegurar a eficiência, a eficácia e a efetividade das atividades de ensino, pesquisa e extensão das Instituições Federais de Ensino.

Magalhães (2016, p. 08), ao pesquisar o "histórico do trabalho do técnico-administrativo em diálogo com marcos históricos e legais da educação profissional", define esses profissionais como "aquele profissional, em qualquer nível de escolaridade e/ou desenvolvendo qualquer atribuição não docente, e que empresta esforço educativo na sua atuação dentro do contexto escolar" (MAGALHÃES, 2016, p. 17). A partir dessa definição e análise de documentos legais da EPT no Brasil a autora constata a presença de não docentes desde o considerado marco da EPT no Brasil, a criação Escolas de Aprendizes Artífices (1909). Também evidencia em cada período o aumento da presença desses profissionais, porém com diferentes nomenclaturas do cargo, o que por si só dificultam "a identificação do trabalho desenvolvido por esse profissional, bem como, obstruem o processo de construção da sua identidade, reflexo da omissão das políticas públicas [...] na valorização e no reconhecimento desse profissional como também agentes do processo educativo" (MAGALHÃES, 2016, p. 17).

Diante desse histórico secular da presença de trabalhadores não docentes na EPT e dos 16 anos de existência do PCCTAE; das mudanças de concepção tanto da instituição de trabalho, quanto da regulamentação do cargo, aos TAEs compete ocuparem seus espaços nas discussões sobre qual instituição eles querem trabalhar, que tipo de ensino, pesquisa e extensão querem ajudar a construir. $E$, também, é na operacionalização dessas novas possibilidades construída e conquistada, que a categoria se consolidará ou não como educadora e agente fundamental na facilitação do ensino e promotor de pesquisa e extensão.

\section{PROCEDIMENTOS METODOLÓGICOS}

Neste trabalho analisamos as diferentes edições da coletânea de artigos "Gestão Pública: a visão dos Técnicos Administrativos em Educação das Universidades Públicas e Institutos Federais (GPTAE)", que tem a missão de "fomentar e despertar o interesse em pesquisa acadêmica e científica realizada pelos Técnicos Administrativos em Educação (TAE) de Instituições Públicas de Ensino Básico, Técnico e Tecnológico e em específico ao Ensino Superior (IES) no Brasil" (GPTAE, 2021). Para submissão de artigos é obrigatório autoria principal ser de profissionais pertencentes às carreiras dos técnicos administrativos em educação de instituições de ensino públicas. Por isso usamos para definir os demais dados sempre o primeiro autor.

A GPTAE no ano de 2020 publicou o seu sétimo volume. A primeira edição foi no ano de 2014. A partir do quarto volume, publicado no ano de 2017, os artigos começaram a ser organizados por temáticas. Percebemos que ao longo dos anos os títulos das temáticas vão sendo adaptados e 
adicionados novos para melhor classificação, mas sempre mantendo a essência. A seguir apresentamos as temáticas do ano de 2020:

1. Gestão pública nas universidades públicas e institutos federais;

2. Gestão de pessoas nas instituições de ensino superior e equivalentes;

3. Capacitação e qualificação de servidores das instituições de ensino superior e equivalentes;

4. Práticas de ensino, pesquisa e extensão;

5. Ética na gestão pública e os princípios da administração pública;

6. Realidade das instituições federais de ensino e orçamento público;

7. Os técnicos administrativos nas instituições de ensino: aspectos sobre qualidade de vida, segurança, saúde e cultura organizacional no ambiente laboral das instituições de ensino superior e equivalentes;

8. A sustentabilidade ambiental nas instituições públicas de ensino superior;

9. Gestão de documentos públicos;

10. Tecnologia da informação, inclusão e inovação;

11. Cultura e comunicação;

12. Direitos humanos e políticas públicas (GPTAE, 2020, p. 01).

É também a partir do quarto volume que a estrutura dos textos apresenta título, resumo, introdução, desenvolvimento e considerações finais. Nos três primeiros volumes (2014, 2015 e 2016) as obras não eram divididas por temáticas e a estrutura do texto contava com título, introdução, desenvolvimento e considerações finais. Por isso, para analisar quais as temáticas que os TAEs mais escrevem, utilizaremos apenas os dados de 2017 a 2020, para não incorrer em inconsistências, pois, como é explicado na apresentação da sétima edição,

Os textos deste volume, a exemplo dos anteriores, mantém a mesma estrutura em termos de organização, por isso reúne os trabalhos segundo as áreas temáticas foco predominante de abordagem da gestão pública, sem desconsiderar que a maioria dos trabalhos aqui reunidos poderia transitar por outras áreas de estudos da gestão pública, além daquela a que foi associado, dada a interdisciplinaridade que singulariza os estudos desse campo. (Assis e Silva, 2020, p. 13, grifo nosso).

Diante disso, e para alcançar nossos objetivos propostos para a pesquisa, utilizamos o procedimento de tabulação dos dados, com os seguintes parâmetros: a) ano da coletânea, b) título do artigo, c) autoria, d) cargo, e) instituição e d) organização temática (derivada da classificação da própria coletânea). A seguir apresentaremos os resultados dessa pesquisa.

\section{RESULTADOS E DISCUSSÕES}

Nas coletâneas mapeamos TAEs lotados em Universidades Federais, Institutos Federais, Colégio Pedro II e de Universidades Estaduais. Todas as coletâneas já publicadas apresentam um total de 
126 artigos. No Quadro 01 podemos observar o quantitativo de artigos por ano e característica de instituição.

Nesses 7 anos de coletânea 54\% dos artigos tiveram como autor principal TAEs lotados nas Universidades Federais, 37\% Institutos Federais e 7\% Universidades Estaduais (Figura 01).

Quadro 01: Totais de artigos por ano de publicação e Instituição de lotação.

\begin{tabular}{|l|r|r|r|r|r|r|r|r|}
\hline \multicolumn{1}{|c|}{ Instituição } & $\mathbf{2 0 1 4}$ & $\mathbf{2 0 1 5}$ & $\mathbf{2 0 1 6}$ & $\mathbf{2 0 1 7}$ & $\mathbf{2 0 1 8}$ & $\mathbf{2 0 1 9}$ & $\mathbf{2 0 2 0}$ & \multicolumn{1}{c|}{ Total } \\
\hline Universidade Federal & 7 & 7 & 9 & 18 & 11 & 6 & 10 & 68 \\
\hline Instituto Federal & 3 & 10 & 8 & 8 & 9 & 6 & 3 & 47 \\
\hline Colégio Pedro II & 0 & 0 & 0 & 0 & 0 & 1 & 0 & 1 \\
\hline Universidade Estadual & 0 & 0 & 0 & 0 & 0 & 7 & 2 & 9 \\
\hline Outros & 0 & 0 & 1 & 0 & 0 & 0 & 0 & 1 \\
\hline \multicolumn{1}{|c|}{ Total } & $\mathbf{1 0}$ & $\mathbf{1 7}$ & $\mathbf{1 8}$ & $\mathbf{2 6}$ & $\mathbf{2 0}$ & $\mathbf{2 0}$ & $\mathbf{1 5}$ & $\mathbf{1 2 6}$ \\
\hline
\end{tabular}

Fonte: Elaborado pelos autores.

O Campo "outros" (Figura 01) se refere a um artigo que não apresentava cargo/instituição do autor e quando pesquisado o nome no portal da transparência, não aparecia como servidor público, não se encaixando aos nossos parâmetros da pesquisa, sendo assim, foi excluído dos próximos dados deste artigo. Também excluímos o campo "Colégio Pedro II", por somente apresentar um artigo e o campo "Universidade Estadual", pois só passam a publicar no ano de 2019, assim construímos um panorama dos TAEs regidos pelo PCCTAE de UFs e IFs, que representam $91 \%$ das publicações.

Os TAEs lotados nas Universidades apresentam mais publicações ao logo dos anos que os lotados em Institutos. Somente em 2015 que os TAEs de IFs publicam mais que os das UFs. Em 2019 o número de textos de lotados em IFs e Ufs foi o mesmo. A Figura 02 divide as publicações por instituição e por ano de publicação.

Por mais que os TAEs de UFs e IFs sejam regidos pela mesma legislação, nosso trabalho tem como objeto os TAEs nos IFs. Dessa forma, quanto às temáticas, analisamos apenas os artigos de TAEs lotados nos IFs. Trata-se do total de 26 artigos cujo corte temporal é a partir de 2017, quando os artigos passaram a ser divididos em temáticas.

Figura 01: Artigos por Instituição.

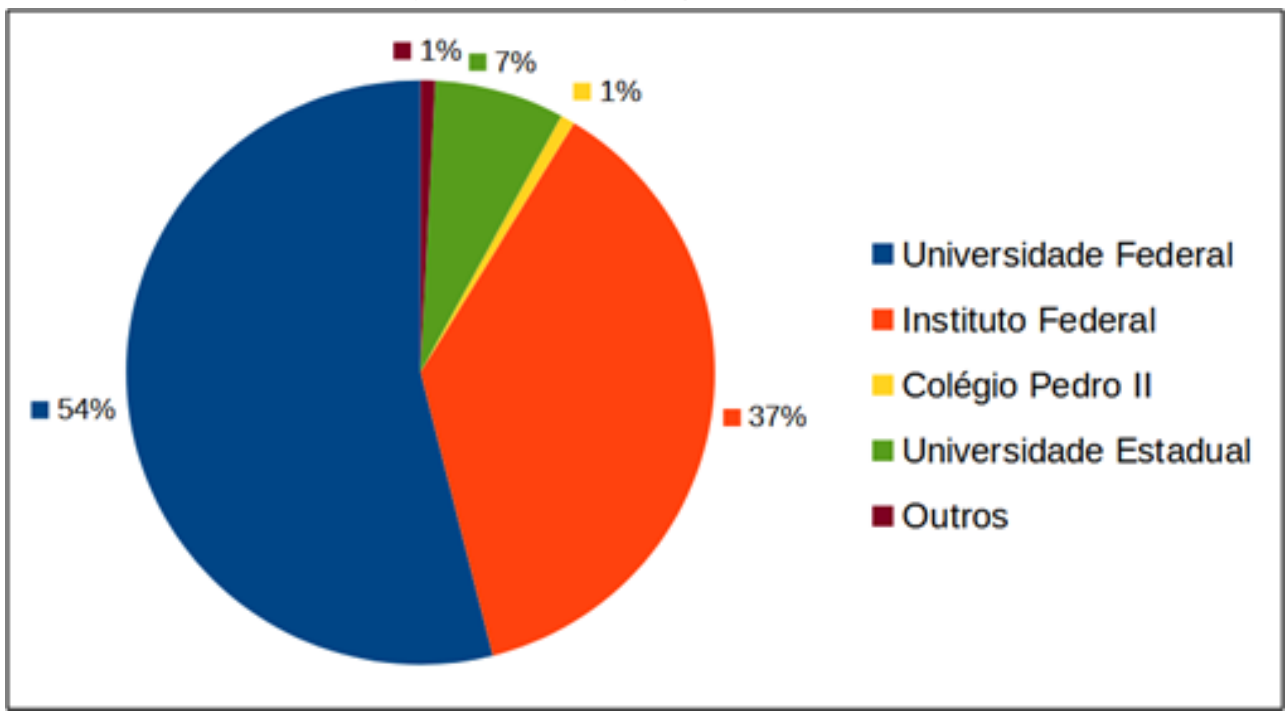

Fonte: Elaborado pelos autores. 
Figura 02: Artigos TAEs Ufs x IFs.

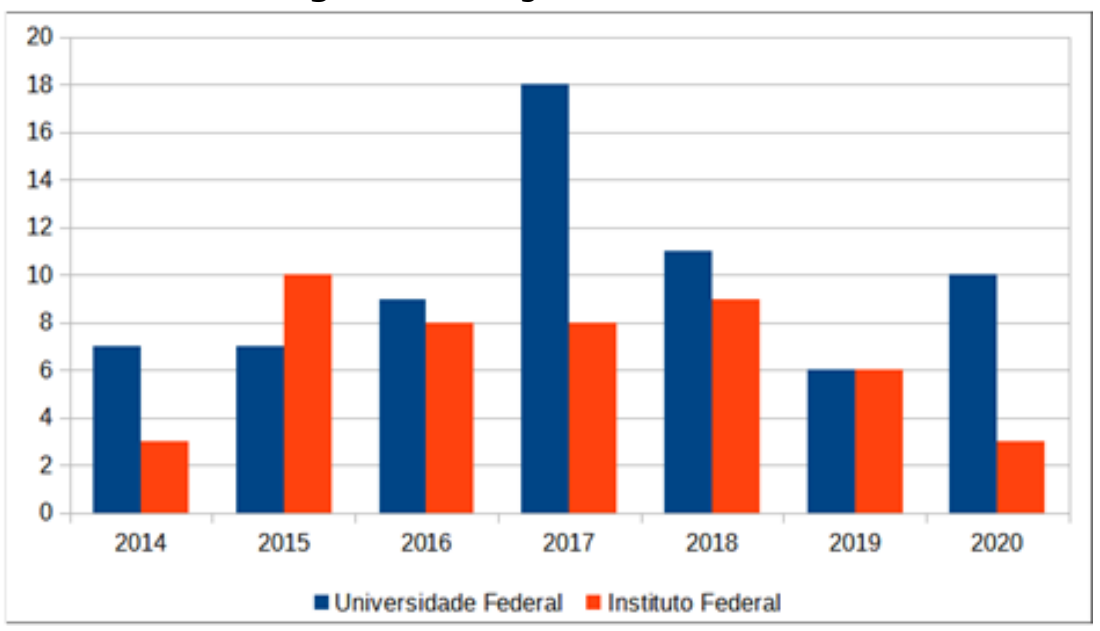

Fonte: Elaborado pelos autores.

Os 26 artigos estão distribuídos em 8 das 12 temáticas apresentadas pela coletânea. As temáticas "Cultura e comunicação", "Gestão de documentos públicos", "Ética na gestão pública e os princípios da administração pública" e "Gestão de pessoas nas IES e equivalentes" são as que não apresentam textos publicados. A temática com maior número de textos é a "Gestão pública nas universidades públicas e institutos federais", representando $27 \%$, seguida, com $23 \%$, pela temática "Os técnicos administrativos nas IE: aspectos sobre qualidade de vida, segurança, saúde e cultura organizacional no ambiente laboral das IES e equivalentes". A terceira temática mais frequente se refere a "Realidade das instituições federais de ensino e orçamento público", com 15\%. A Figura 03 ilustra os temas e as incidências de publicações.

Considerando o escopo da pesquisa da qual parte este trabalho, chama a atenção que o tema "Práticas de ensino, pesquisa e extensão" seja apenas o quarto, com $12 \%$ dos textos. Ou seja, se considerarmos que os trabalhos apresentados na coletânea expressem resultados de pesquisa realizados pelos TAEs - em capacitações de especialização, mestrado ou doutorado ou mesmo em projetos de pesquisa desenvolvidos em suas instituições - mostra-se que o tripé que sustenta as instituições - ensino, pesquisa e extensão - suscita pouco interesse de pesquisa por parte dessa categoria.

Figura 03: Publicações dos TAEs de IFs por temáticas.

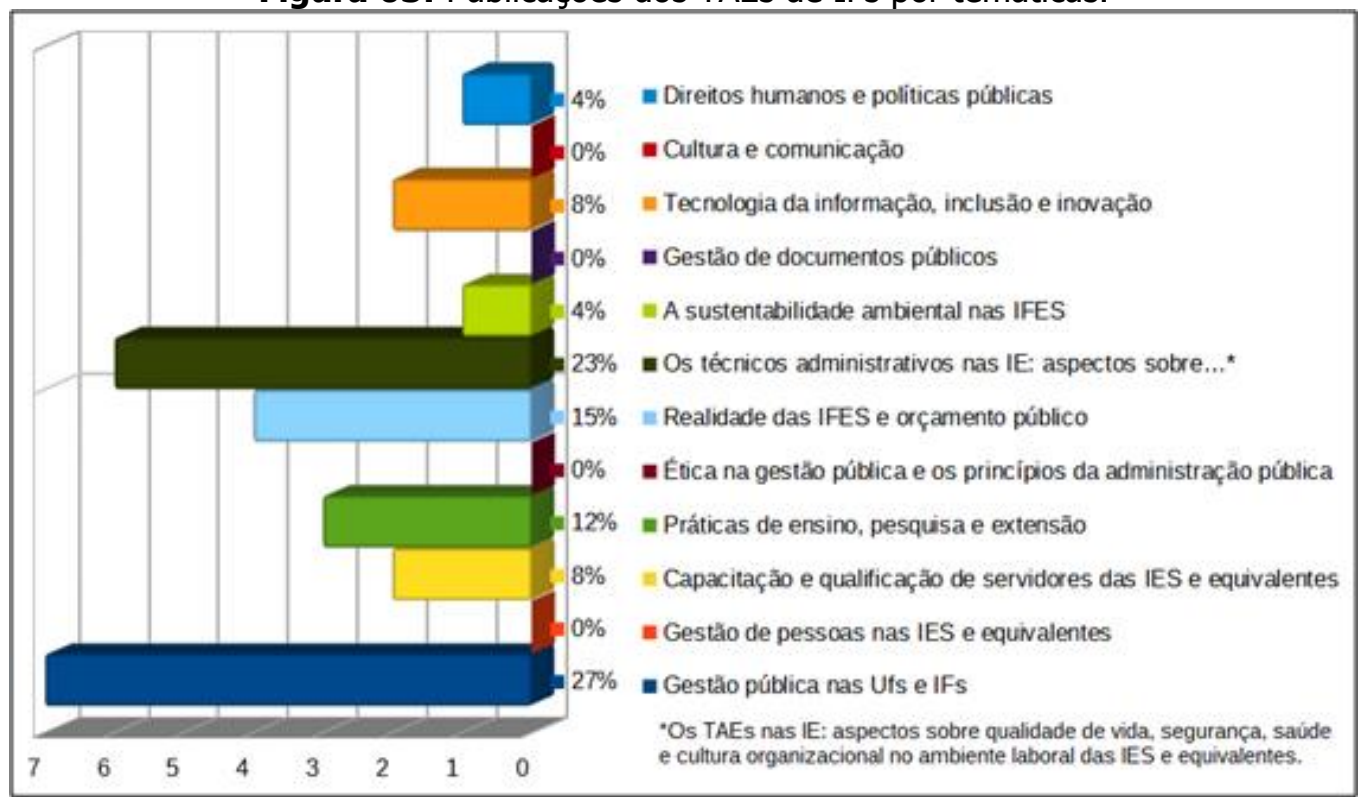

Fonte: Elaborado pelos autores. 


\section{CONSIDERAÇÕES FINAIS}

A busca por aferir e apreender o que os trabalhadores TAEs tem produzido intelectualmente acerca de seus fazeres laborais cotidianos têm importância significativa, pois dá visibilidade na arena do debate público nos espaços de publicações, a quem é subtraído de visibilidade da prática pedagógica nos espaços institucionais da ação pedagógica cotidiana e formal.

Os artigos prospectados nos números da "Gestão Pública: a visão dos Técnicos Administrativos em Educação das Universidades Públicas e Institutos Federais (GPTAE)", comprovam, pela quantidade de temáticas de estudos abordadas por esses trabalhadores, a heterogeneidade dessa categoria, . Porém há poucos escritos sobre o tripé (ensino, pesquisa e extensão) institucional. As preferências de escrita são por temas ligados ao trabalho cotidiano, ou seja, o fazer diretamente executado e a administração das Instituições.

Os TAEs são uma categoria constituída de várias profissões, com definição geral dos cargos que compõe o PCCTAE em comum e os colocam agentes do ensino, pesquisa e extensão, o que lhes dão significativa potencialidade de contribuição nessas atividades-fim da instituição. Todavia as poucas publicações sobre esses temas, ao menos na coletânea GPTAE, livro que vem se tornando referência de publicações de TAEs, podem demonstrar que esse profissional ainda é descaracterizado da função de educador ou/e o próprio trabalhador não se reconhece como educador. E é com essa experiência metodológica que partiremos para a próxima etapa da nossa pesquisa de mestrado: trabalho de campo e a produção do produto educacional.

\section{REFERÊNCIAS}

ASSIS, Wanderlice da Silva et al (org.). Gestão pública [e-book]: a visão dos técnicos administrativos em educação das universidades públicas e institutos federais. 6. ed. Bauru: Gradus, 2019. 323 p. Disponível em: https://bit.ly/3pPrNTE. Acesso em: 17 fev. 2021.

ASSIS, Wanderlice da Silva et al (org.). Gestão pública: a visão dos técnicos administrativos em educação das universidades públicas e institutos federais. 7. ed. Campo Grande: Oeste, 2020. Disponível em: https://bit.ly/3aJjep8. Acesso em: 17 fev. 2021.

BRASIL. Decreto n० 2.208, de 17 de abril de 1997. Regulamenta 0 § $2 \circ$ do art. 36 e os arts. 39 a 42 da Lei no 9.394, de 20 de dezembro de 1996, que estabelece as diretrizes e bases da educação nacional. Brasília, Disponível em: https://bit.ly/3pNLPxM. Acesso em: 15 jan. 2020.

BRASIL. Decreto no 5.824, de 29 de junho de 2006. Estabelece os procedimentos para a concessão do Incentivo à Qualificação e para a efetivação do enquadramento por nível de capacitação dos servidores integrantes do Plano de Carreira dos Cargos TécnicoAdministrativos em Educação, instituído pela Lei no 11.091, de 12 de janeiro de 2005. Brasília, Disponível em: https://bit.ly/37FZkcP. Acesso em: 15 jan. 2020.

BRASIL. LEI No 11.091, DE 12 DE JANEIRO DE 2005. Dispõe sobre a estruturação do Plano de Carreira dos Cargos Técnico-Administrativos em Educação, no âmbito das Instituições Federais de Ensino vinculadas ao Ministério da Educação, e dá outras providências. Brasília, Disponível em: https://bit.ly/2P4vPel. Acesso em: 18 nov. 2019.

BRASIL. Lei no 11.892, de 29 de dezembro de 2008. Institui a Rede Federal de Educação Profissional, Científica e Tecnológica, cria os Institutos Federais de Educação, Ciência e 
Tecnologia, e dá outras providências. Brasília, Disponível em: https://bit.ly/2ZHv3G3. Acesso em: 05 out. 2019.

BRASIL. LEI No 8.112, DE 11 DE DEZEMBRO DE 1990. Dispõe sobre o regime jurídico dos servidores públicos civis da União, das autarquias e das fundações públicas federais. Brasília, Disponível em: http://www.planalto.gov.br/ccivil_03/leis/l8112cons.htm. Acesso em: 18 nov. 2019.

CABRAL, Bruno Rodrigues et al (org.). Gestão pública: a visão dos técnicos administrativos em educação das universidades públicas e institutos federais. 5. ed. São Carlos: Pedro \& João, 2018. Disponível em: https://bit.ly/3bB7pAy. Acesso em: 17 fev. 2021.

CHAVES, Elisângela André de Oliveira et al (org.). Gestão pública: a visão dos técnicos administrativos em Educação das Universidades Públicas e Institutos Federais. 2. ed. Salvador: Pontocom, 2015. Disponível em: https://bit.ly/3dDJjI8. Acesso em: 16 fev. 2021.

CICHACZEWSKI, João Carlos. UMA HISTÓRIA POR FAZER-SE: o sentido da formação profissional nos IFs. Blumenau: Produto Educacional (Mestrado Profissional em Educação Profissional e Tecnológica), 2020. 87 p. Disponível em: https://bit.ly/3shO7XO. Acesso em: 20 jul. 2020.

FRIGOTTO, Gaudêncio (org.). Institutos Federais de Educação, Ciência e Tecnologia: relação com o ensino médio integrado e o projeto societário de desenvolvimento. Rio de janeiro: UERJ, LPP, 2018. 320 p. Disponível em: https://bit.ly/3qQmIMf. Acesso em: 17 out. 2019.

FRIGOTTO, Gaudêncio; CIAVATTA, Maria; RAMOS, Marise. A gênese do Decreto n. 5.154/2004 um debate no contexto controverso da democracia restrita. maio/junho. 2006. Disponível em: https://bit.ly/2NX4Row. Acesso em: 17 out. 2019

FRIGOTTO, Gaudêncio. A relação da educação profissional e tecnológica com a universalização da educação básica. Educ. Soc., Campinas, v. 28, n. 100, p. 1129-1152, Oct. 2007. Disponível em: https://bit.ly/3ujTAzf. Acesso em: 19 out. 2020.

GPTAE, Gestão Pública: A Visão dos Técnicos Administrativos em Educação das Universidades Públicas e Institutos Federais (org.). Missão, objetivos, valores e visão. Disponível em: https://bit.ly/3bvpRuB. Acesso em: 08 fev. 2021.

GPTAE, Gestão Pública: A Visão dos Técnicos Administrativos em Educação das Universidades Públicas e Institutos Federais. COMUNICADO No 6, DE 08 DE JUNHO DE 2020. Disponível em: https://bit.ly/3aJ3R02. Acesso em: 19 fev. 2021.

MAGALHÃES, Caroline Stéphanie Campos Arimateia. TRABALHO EDUCATIVO DO TÉCNICOADMINISTRATIVO DO IFRN/CNAT: CONSENSOS E DISSENSOS. 2016. 173 f. Dissertação (Mestrado) - Curso de Programa de Pós-Graduação em Educação Profissional (Ppgep), Instituto Federal de Educação, Ciência e Tecnologia do Rio Grande do Norte, Natal, 2016. Disponível em: https://bit.ly/3sxA8NR. Acesso em: 14 fev. 2020.

MOURA, Dante Henrique; MAGALHÃES, Caroline Stephanie Campos Arimateia; MAGALHÃES, Ricardo Rodrigues. PROFISSIONAIS DA EDUCAÇÃO NO PNE 2014-2024: acomodação ou conflito de interesses. Anais do III Colóquio Nacional | Eixo Temático I - Políticas em Educação Profissional, Natal, 2015. Disponível em: hhttps://bit.ly/3qMbXuz. Acesso em: 14 fev. 2020.

PACHECO, Eliezer. Fundamentos Político-Pedagógicos dos Institutos Federais: diretrizes para uma educação profissional e tecnológica transformadora. Natal: IFRN, 2015. Disponível em: https://bit.ly/3dF8nyo. Acesso em: 20 fev. 2020. 
RIMÁ, Jacqueline de Castro et al (org.). Gestão pública: a visão dos técnicos administrativos em educação das Universidades Públicas e Institutos Federais. 3. ed. São Carlos: Pedro e João Editores, 2016. Disponível em: https://bit.ly/3aNMs6x. Acesso em: 16 fev. 2021.

SANTOS, Adelmária Ione dos (org.). A gestão pública na visão dos técnicos administrativos em educação das Universidades Públicas e Institutos Federais. São Paulo: Digitalbooks, 2014. Disponível em: https://bit.ly/3khqrQz. Acesso em: 16 fev. 2021.

SANTOS, Geovane Santana dos et al (org.). Gestão pública: a visão dos técnicos administrativos em educação das universidades públicas e institutos federais. 4. ed. São Carlos: Pedro \& João, 2017. Disponível em: https://bit.ly/3pSM9M4. Acesso em: 17 fev. 2021.

Submissão: 07/03/2021

Aceito: 15/09/2021

i Ver Frigotto, 2018, p. 146-147. 